\title{
Sustentabilidade do modelo agrícola da bacia do riacho Faé ${ }^{1}$
}

\author{
Sustainability of agricultural model of Faé watershed using multivariable analysis
}

\author{
Ana Célia Maia Meireles²*, José Ribeiro de Araujo Neto ${ }^{3}$ e Lúcio José de Oliveira ${ }^{3}$
}

\begin{abstract}
Resumo - Este trabalho teve como objetivo avaliar as famílias da parte baixa da bacia hidrográfica do riacho Faé, a partir do modelo agrícola rural existente, utilizando análise multivariada. Foram aplicados questionários do tipo "cross over", com perguntas abertas e fechadas, para a caracterização sócio-econômica e ambiental da região estudada. Para observar as similaridades entre as famílias estudadas aplicou-se a técnica de análises de Agrupamento Hierárquico aos dados. A análise definiu dois grupos bem distintos. O grupo I foi formado por famílias com características tipicamente rurais, envolvendo famílias de baixa renda que desenvolvem as suas atividades produtivas de maneira rudimentar, com o uso de agrotóxicos representando sérios riscos à sustentabilidade do modelo agrícola e, principalmente, à vida dessas famílias. O grupo II demonstrou famílias que, embora localizadas em meio rural, apresentaram características tipicamente urbanas, caracterizadas pela faixa etária predominante jovem, baixa escolaridade e atividade econômica não agrícola. A análise de agrupamento se mostrou eficiente para a distinção dos grupos de famílias homogêneas na área estudada, independentemente de sua localização geográfica.
\end{abstract}

Palavras-chave - Sustentabilidade Ambiental. Análise multivariada. Bacia Hidrográfica.

\begin{abstract}
This study aimed to evaluate the families living in the part of the stream Faé watershed. It was based on the existing agricultural model and it was used the multivariate analysis. Forms "cross-over" types with subjective and objective questions were applied for socio-economic and environmental study area. To observe the similarities between the studied families applied Hierarchical Cluster Analysis to data. It was identified two distinct groups. Group I was formed by families with characteristics typically agriculturalist with low income families developing their productive activities in a rudimentary way. Those families use pesticides and they represent a risk both to support agricultural model and to the lives of those families. Group II was formed by families who, even so located in agricultural environment, present typically urban characteristics. In those families there are many young people, many people with low level of schooling and they have no agricultural economic activity. Cluster analysis was efficient to separate the homogeneous groups of families in the study area regardless of geographic location.
\end{abstract}

Key words - Environmental support. Cluster analysis. Watershed.

\footnotetext{
* Autor para correspondência

'Recebido para publicação em 06/04/2010; aprovado em 10/02/2011

Parte da Dissertação do terceiro autor apresentada no Programa de Pós-Graduação em Engenharia Agrícola da UFC, financiada pelo CNPq ${ }^{2}$ Programa de Pós-Graduação em Engenharia Agrícola/UFC, bolsista PNPD/CAPES, Fortaleza-CE, Brasil, ameireles2003@yahoo.com.br

${ }^{3}$ Instituto Federal de Educação do Ceará, Iguatu-CE, Brasil, junior.bg@bol.com.br
} 


\section{Introdução}

A sustentabilidade ambiental é um atributo de uma entidade espaço-temporal em que se incorpora a relação Sociedade-Natureza. Implica na coexistência harmônica do homem com seu meio ambiente, mediante o equilíbrio de sistemas transformados e criados através da eliminação de detritos. Pressupõe-se a incorporação de conceitos temporais, tecnológicos e financeiros, refletindo um processo dinâmico e aleatório de transações de fluxos de Energia, Matéria e Informação (EMI) entre todos os componentes espaciais (RABELO, 2008).

Do surgimento da agricultura, há cerca de dez mil anos, ao início do século XIX, o crescimento da economia mundial foi predominantemente extensivo, isto é, com produção e população aumentando a taxas muito próximas. Mas isto não quer dizer que crescimento intensivo, com aumento da renda per capita - essência do "modern economic growth (MEG)" de Simon Kuznets só tenha se manifestado nos últimos duzentos anos, após a ascensão da grande indústria (CHRISTOFIDIS, 2003).

A crise ambiental no setor agropecuário, no início deste novo milênio, é profunda e multifacetada. Problemas como: concentração da posse da terra e da renda, êxodo rural, desemprego, erosão e perda da fertilidade dos solos, contaminação dos alimentos, do solo, da água, destruição florestal, bem como o esgotamento dos recursos naturais e a deteriorização dos ecossistemas fazem parte do nosso cotidiano (LOPES et al., 2009).

A inter-relação entre a sustentabilidade, o nível educacional dos pequenos produtores rurais, as condições climáticas locais, o uso da terra, o sistema de produção familiar, a geologia, a qualidade da água de irrigação, a drenagem natural do solo e a comercialização, entre outros, vem sendo amplamente discutidos (BRANCO, 2003; NOGUEIRA; SIMÕES, 2009; SOUZA et al., 2001). Sustentabilidade esta que não significa, simplesmente, a adoção de práticas comuns a toda agricultura desenvolvida no mundo e sim, que sejam avaliadas as limitações e aptidões dos recursos naturais de cada região e as limitações, as aptidões e o desenvolvimento do homem existente nestes locais

Verifica-se, no entanto, nas áreas rurais de todo o Brasil o surgimento da Renda Não-Agrícola e as Famílias de Conta-Própria Pluriativa. Nascimento (2006) conceitua Renda Não-Agrícola como o somatório das rendas totais do trabalho não-agrícola, como as transferências governamentais (aposentadorias e pensões) e outros tipos de fontes (programas sociais oficiais, rendimentos financeiros, aluguéis, dentre outros). Família de Conta-Própria Pluriativa é aquela família em que pelos menos um membro trabalha por conta própria na agricultura e outro se encontra ocupado em qualquer um dos demais setores da economia. Nas unidades familiares pluriativas é intenso o processo de proletarização dos produtores familiares.

A avaliação das interações entre as diversas variáveis ambientais, sociais e econômicas que definem sustentabilidade tem sido, nos últimos anos, largamente realizada utilizando métodos de estatística multivariada. A análise de agrupamento, uma das técnicas de análise multivariada, tem se mostrado uma eficiente ferramenta de estudo em trabalhos científicos relacionados com a área social e de recursos naturais (ALBUQUERQUE et al., 2006; LOPES et al., 2009; MARTEL et al., 2003; SOUZA et al., 2003).

Neste sentido, o presente trabalho teve como objetivo elaborar, a partir de análise multivariada de indicadores agrícolas, ambientais e sociais, o comportamento das famílias amostradas na parte baixa da bacia hidrográfica do riacho Faé, em decorrência do modelo agrícola rural existente.

\section{Material e métodos}

A área de estudo se localiza na parte baixa da bacia hidrográfica do riacho Faé. Este riacho é um tributário da margem esquerda do açude Orós, que por sua vez faz parte do sistema de abastecimento de água do médio e baixo Jaguaribe e da Região Metropolitana de Fortaleza. O riacho Faé também integra a rede de drenagem da bacia do Alto Jaguaribe, localizada na porção meridional do Estado do Ceará entre os quadrantes $7,44^{\circ} \mathrm{S}-40,87^{\circ} \mathrm{W}$ e $5,39^{\circ} \mathrm{S}-38,79^{\circ} \mathrm{W}$. Na Figura 1 visualiza-se o mapeamento da área geográfica abrangida por este estudo, que compreende 64.690,19 hectares.

Conforme a classificação de Köppen, a bacia do riacho Faé se encontra inserida em uma zona climática do tipo BSw'h', clima semiárido muito quente com precipitações máximas de outono, e temperatura média mensal sempre superior a $18^{\circ} \mathrm{C}$.

A bacia hidrográfica do riacho Faé se encontra inserida na mesorregião Centro-Sul cearense, composta pelas microrregiões de Iguatu, Lavras da Mangabeira e Várzea Alegre, historicamente conhecida pela importância do algodão na região. Tem no arroz irrigado o principal destaque da agricultura atual. A cultura do algodão vem sendo reintroduzida, mas em dimensão bem menor que no passado. Ainda merece destaque na região o feijão, mandioca, milho e banana, somente esta última sendo cultivada de forma comercial. Também a pecuária é atividade importante, na qual se destacam a bacia leiteira, a bovinocultura de corte e a avicultura (FERREIRA, 2006). 


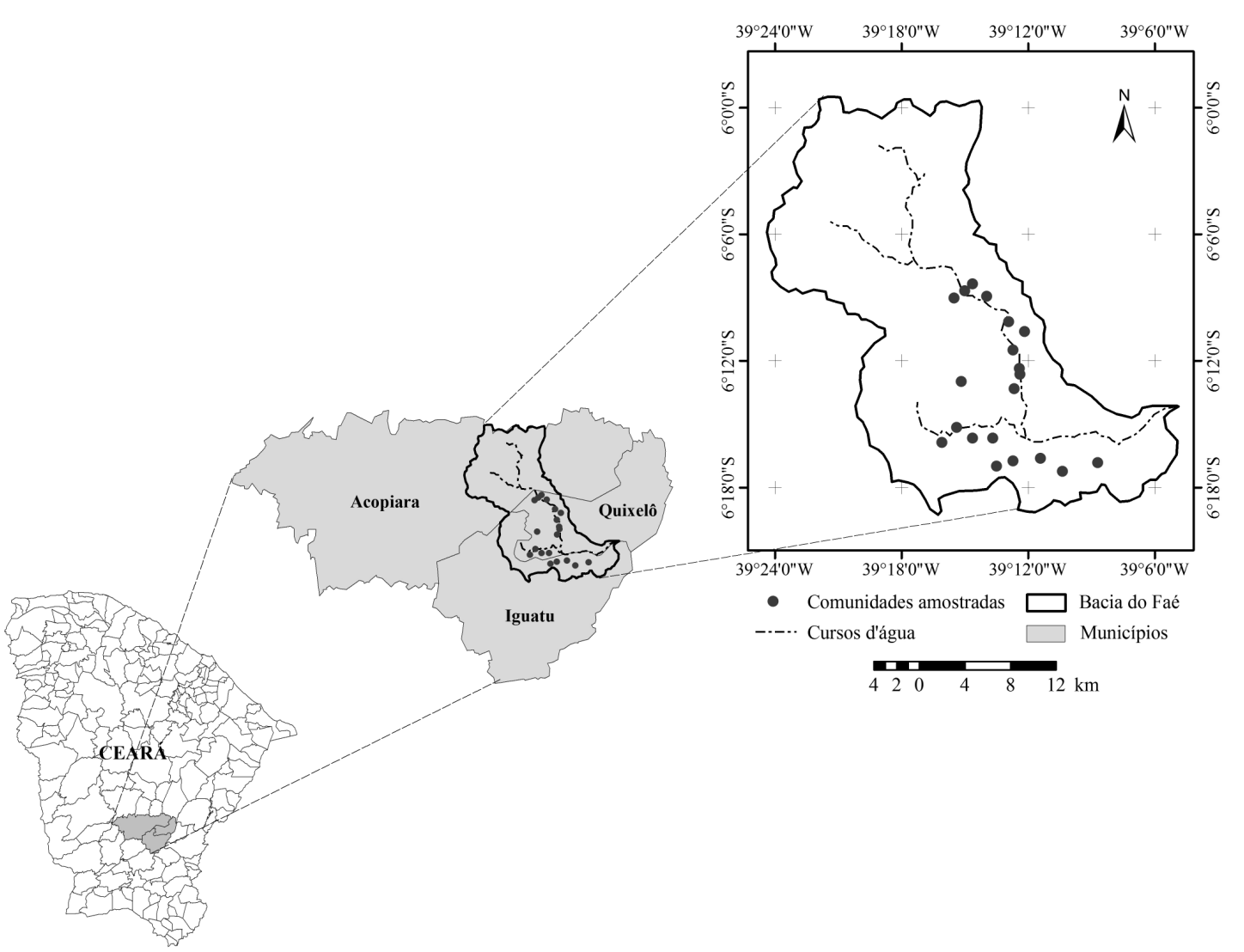

Figura 1 - Localização dos pontos de amostragem inseridos na parte baixa da bacia hidrográfica do riacho Faé

$\mathrm{Na}$ realização da amostragem deste trabalho optou-se pela Amostra Aleatória Simples - AAS, com o uso da técnica probabilística, onde todos os elementos da população têm igual chance, diferente de zero, de fazer parte da amostra (MOORE; McCABE, 2002). A parte baixa da bacia hidrográfica do riacho Faé conta com uma população composta por um universo de 1.861 famílias, conforme dados fornecidos pelo Sistema de Informação Ambulatorial do Sistema Único de Saúde, através da Prefeitura Municipal de Quixelô, em setembro de 2008.

Considerando a população total $(\mathrm{N})$ de 1.861 , um erro amostral (d) definido em 0,05, o nível de confiança de 0,95 , com desvio padrão $(Z)$ igual a 1,96 e os percentuais dos elementos favoráveis (p) e desfavoráveis (q) da amostra ao atributo pesquisado estimados em $50 \%$ respectivamente, o tamanho da amostra foi calculado através da equação 1 descrita abaixo, também utilizada por Lopes (2008):

$$
n=\frac{Z^{2} p q N}{d^{2}(N-1)+Z^{2} p q}
$$

Através da equação o tamanho da amostra com representatividade para a bacia em estudo é de, no mínimo, 92 famílias. Para a coleta de dados na parte baixa da bacia em estudo foi aplicado um questionário do tipo "cross over", também chamado de "cross-section". Esta terminologia é cabível aos estudos "exploratórios" ou "ex-post-facto", pois o pesquisador se limitará a detectar o que aconteceu, não manipulando variáveis e, no que se refere ao tempo, poderá ser desenvolvido ocasionalmente, com futura repetição (DUTRA; SAUAIA, 2007). Na Tabela 1 estão listadas as comunidades visitadas com suas respectivas informações geográficas.

Mesmo considerando 92 famílias o número representativo da amostra calculada, resolveu-se aplicar a um universo de 237 famílias, distribuídas em 20 comunidades (TAB. 1), devido à facilidade do acesso às famílias e a disponibilidade da equipe de campo. Os dados obtidos foram tabulados em Planilha Excel e tratados através da Análise de Agrupamento Hierárquico (Cluster Analysis) utilizando o software Statistical Package for the Social Sciences (SPSS) versão 16.0 . 
A partir dos indicadores agrícolas, ambientais e sociais que se encontram listados na Tabela 2, utilizou-se a
Análise de Agrupamento Hierárquico, através do algoritmo de Ward, para estabelecer a formação dos grupos.

Tabelas 1 - Coordenadas geográficas das comunidades existentes na parte baixa da bacia hidrográfica do riacho Faé

\begin{tabular}{|c|c|c|c|c|}
\hline Comunidade & Identificação & Latitude & Longitude & População (Famílias) \\
\hline Angicos I & ANG & $6^{\circ} 8^{\prime} 59,5 ’ \mathrm{~S}$ & $39^{\circ} 15^{\prime} 27,9^{\prime \prime} \mathrm{W}$ & $53 *$ \\
\hline Angicos II & $\mathrm{ANG}$ & 68'26,4”'S & $39^{\circ} 14^{\prime} 42^{\prime \prime} \mathrm{W}$ & $74^{*}$ \\
\hline Altos & ALT & $6^{\circ} 13^{\prime} 19,3$ ”'S & $39^{\circ} 12^{\prime} 35,44^{\prime \prime} \mathrm{W}$ & 112 \\
\hline Vila Antonico & ANT & $6^{\circ} 15^{\prime} 50,1$ 'S & $39^{\circ} 16^{\prime} 04^{\prime \prime} \mathrm{W}$ & 354 \\
\hline Botão & BTA & $6^{\circ} 16^{\prime} 45,2 ” S$ & $39^{\circ} 12^{\prime} 41,2^{\prime \prime} \mathrm{W}$ & $170 *$ \\
\hline Canafístula & $\mathrm{CNF}$ & $6^{\circ} 12^{\prime} 58,4$ ”S & $39^{\circ} 15^{\prime} 07,7^{\prime \prime} \mathrm{W}$ & 57 \\
\hline Carnalbinha & $\mathrm{CNB}$ & $6^{\circ} 10^{\prime} 03,5^{\prime \prime} \mathrm{S}$ & $39^{\circ} 12^{\prime} 51,9 ’ \mathrm{~W}$ & 104 \\
\hline Currais Novos & CRN & $6^{\circ} 17^{\prime} 17^{\prime \prime} \mathrm{S}$ & $39^{\circ} 10^{\prime} 21,9^{\prime \prime} \mathrm{W}$ & 244 \\
\hline Faé & FAE & $6^{\circ} 11^{\prime} 26,2$ 'S & $39^{\circ} 12^{\prime} 41^{\prime \prime} \mathrm{W}$ & 70 \\
\hline Juliões & JLI & $6^{\circ} 8^{\prime} 41,8 ’ \mathrm{~S}$ & $39^{\circ} 14^{\prime} 58,6^{\prime \prime} \mathrm{W}$ & $*$ \\
\hline Lagoa Redonda & LRD & $6^{\circ} 16^{\prime} 57,9 ’ \mathrm{~S}$ & $39^{\circ} 13^{\prime} 28,5^{\prime \prime} \mathrm{W}$ & $*$ \\
\hline Matapasto & MTP & $6^{\circ} 16^{\prime} 47,6^{\prime \prime} \mathrm{S}$ & $39^{\circ} 08^{\prime} 38,6^{\prime \prime} \mathrm{W}$ & 242 \\
\hline Paus de Leite & PDL & $6^{\circ} 10^{\prime} 38^{\prime \prime} \mathrm{S}$ & $39^{\circ} 12^{\prime} 0,7^{\prime \prime} \mathrm{W}$ & $73 *$ \\
\hline Recanto & $\mathrm{RCT}$ & $6^{\circ} 15^{\prime} 10,9$ 's & $39^{\circ} 15^{\prime} 23,9^{\prime \prime} \mathrm{W}$ & 39 \\
\hline Sítio & SST & $6^{\circ} 12 ’ 34 ” S$ & $39^{\circ} 12^{\prime} 19,4 ’ \mathrm{~W}$ & 62 \\
\hline Santa Maria & $\mathrm{SM}$ & $6^{\circ} 8^{\prime} 52,3 ” S$ & 3913'57,7’'W & $*$ \\
\hline Sítio Ilha & STI & $6^{\circ} 16^{\prime} 37,1$ 's & $39^{\circ} 11^{\prime} 19,2^{\prime \prime} \mathrm{W}$ & 37 \\
\hline Tapuios & TPO & $6^{\circ} 12^{\prime} 23,9 " \mathrm{~S}$ & $39^{\circ} 12^{\prime} 19,4 ’ \mathrm{~W}$ & $*$ \\
\hline Vila dos Firminos & VDF & $6^{\circ} 15^{\prime} 40,3^{\prime \prime} \mathrm{S}$ & $39^{\circ} 14^{\prime} 33,8^{\prime \prime} \mathrm{W}$ & $170 *$ \\
\hline Acampamento & $\mathrm{ACP}$ & $6^{\circ} 15^{\prime} 40,3 " \mathrm{~S}$ & $39^{\circ} 13^{\prime} 38,9^{\prime \prime} \mathrm{W}$ & $*$ \\
\hline
\end{tabular}

Fonte: Sistema de Informação Ambulatorial do Sistema Único de Saúde; (*) Comunidades agregadas no mesmo posto de saúde

Tabela 2 - Indicadores agrícolas, ambientais e sociais da parte baixa da bacia hidrográfica do riacho Faé

\begin{tabular}{ccc}
\hline Indicadores Agrícolas & Indicadores Ambientais & Indicadores Sociais \\
\hline Uso de irrigação & Fonte d'água para consumo Humano & Idade \\
Método de irrigação & Cuidados durante o uso de agrotóxicos & Grau de Instrução \\
Manejo do solo & Destino das embalagens vazias de agrotóxicos & Renda Familiar \\
Uso de agrotóxicos & Ocorrência de intoxicação devido ao uso de agrotóxicos & Situação Fundiária \\
Observa período de carência dos & Ogrotóxicos de óbitos devido ao uso de Agrotóxicos & \\
& Preserva meio ambiente \\
Recebe orientação técnica para & Ocorrência de Desmatamento \\
o uso de agrotóxicos & Destino do esgoto domiciliar \\
& Ocorrência de lixão \\
\end{tabular}


As variáveis foram agrupadas com base no grau de semelhança para classificação em grupos similares. Como as variáveis classificatórias escolhidas são variáveis reais e, portanto, são mensuradas em uma escala de intervalos, convencionou-se adotar uma medida de distância com propriedades métricas, tendo a escolha recaída no Quadrado da Distância Euclidiana (Eq. 2).

$$
d e=\left[\sum_{j=1}^{n}\left(P_{p, j}-P_{k, j}\right)^{2}\right]^{0,5}
$$

em que: de é a Distâcia Euclidiana, $\mathrm{P}_{\mathrm{p}, \mathrm{j}}$ e $\mathrm{P}_{\mathrm{k}, \mathrm{j}}$ são variáveis quantitativas $\mathrm{j}$ das observações $\mathrm{p}$ e k, respectivamente.

\section{Resultados e discussão}

Na Figura 2 tem-se um desenho esquemático dos grupos de famílias semelhantes formados a partir da análise de agrupamento. $\mathrm{O}$ número de agrupamentos das famílias foi definido tomando-se por base a variação percentual entre os coeficientes dos grupos consecutivos listados na Tabela 3 . Observa-se que a primeira maior variação entre os coeficientes foi de 166,567, ou seja, 3123,355 - 2956,788, e ocorreu na passagem da formação do 3 para 2 grupo.

Neste caso, o ponto ótimo de corte no dendrograma localiza-se na distância re-escalonada acima do valor de 10,59, correspondendo à formação de dois grupos.

$\mathrm{Na}$ Tabela 4 tem-se as informações sobre os grupos formados após o corte no dendrograma. Os grupos formados ocorreram independentemente da localização geográfica das respectivas famílias. O grupo I reuniu

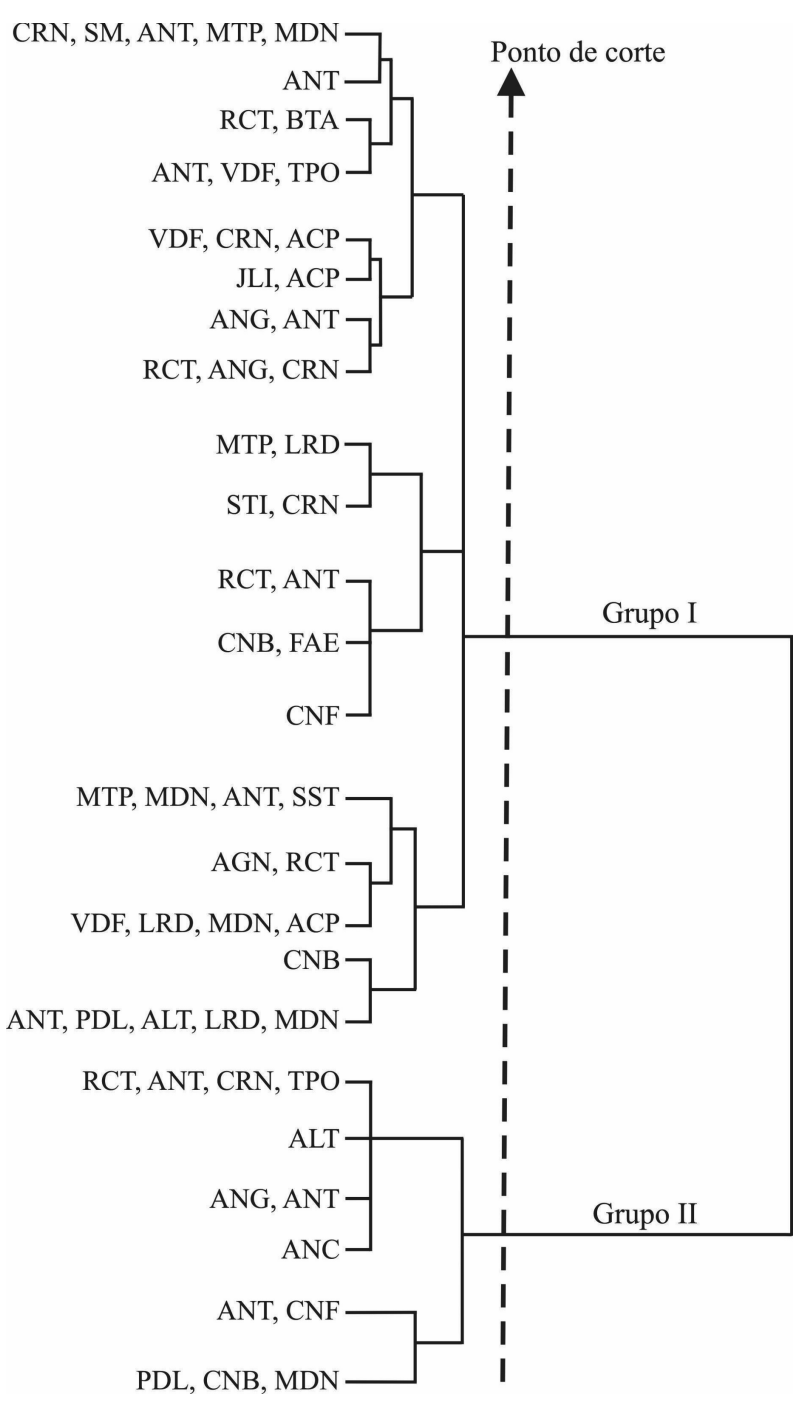

Figura 2 - Representação esquemática dos grupos similares das famílias, segundo as comunidades predominantes na parte baixa da bacia do riacho Faé, gerado pela técnica de análise de agrupamento (SPSS, v.16)

Tabela 3 - Variação do coeficiente de aglomeração para análise hierárquica de agrupamentos

\begin{tabular}{cccc}
\hline Número de agrupamentos & Coeficientes & Variação \% no coeficiente para o próximo nível & Distância reescalonada \\
\hline 10 & 2163,609 & 89,074 & 6,130930 \\
9 & 2252,683 & 91,909 & 6,294234 \\
8 & 2344,592 & 106,988 & 7,162829 \\
7 & 2451,58 & 113,354 & 7,551880 \\
6 & 2565,322 & 122,069 & 8,031540 \\
5 & 2687,391 & 133,354 & 8,681590 \\
4 & 2820,745 & 136,043 & 8,836484 \\
3 & 2956,788 & 166,567 & 10,594758 \\
2 & 3123,355 & 416,645 & 25,000000 \\
\hline
\end{tabular}


197, representando $83,2 \%$ do total de famílias visitadas e o grupo II foi formado com 40 famílias, equivalendo a $16,8 \%$ do total entrevistado.

Tabela 4 - Grupos formados após o corte no dendrograma

\begin{tabular}{ccc}
\hline Grupo & Número de Famílias & $\%$ \\
\hline I & 197 & 83,2 \\
II & 40 & 16,8 \\
\hline Total & 237 & 100 \\
\hline
\end{tabular}

\section{Formação do Grupo I}

O primeiro grupo formado (Grupo I) envolveu aproximadamente $50 \%$ das variáveis trabalhadas na matriz. Foram responsáveis por este agrupamento as seguintes características: renda familiar, uso da irrigação, uso de agrotóxicos, cuidados durante o uso de agrotóxicos, conhecimento e respeito ao período de carência dos produtos, recebimento de orientação técnica para usar agrotóxicos, destino das embalagens vazias de agrotóxicos, ocorrência de intoxicação na família devido ao uso de agrotóxicos, ocorrência de morte na família devido ao uso de agrotóxicos, conhecimento de área sem ter sido desmatada nas imediações de suas residências ocorrência de voçoroca e de depósito de lixo nas imediações da residência.

Neste grupo, aproximadamente $70 \%$ das famílias declaram renda de até 1 salário mínimo; o sistema de irrigação por inundação; 98,5\% utilizam agrotóxicos e esse mesmo percentual declarou não observar nenhum tipo de cuidado durante o uso dos produtos; aproximadamente $81,4 \%$ não recebem orientação técnica para trabalhar com agrotóxicos; cerca de $96,5 \%$ jogam as embalagens vazias de agrotóxicos no meio ambiente; $29,6 \%$ declararam que já houve casos de intoxicação na família devido ao uso de agrotóxicos e aproximadamente os mesmos percentuais declararam a ocorrência de morte na família devido ao uso de agrotóxicos; $67,4 \%$ afirmaram que não haviam observado a ocorrência de voçoroca nas imediações de suas residências e cerca de $56,8 \%$ afirmaram não verificar a ocorrência de depósito de lixo nas suas proximidades. Ainda dos entrevistados desse grupo, 62,8\% não preservam o meio ambiente e somente $28,3 \%$ conhecem alguma área sem ter sido desmatada.

Verifica-se que a renda familiar do grupo I está compatível com a renda dos agricultores familiares que, conforme Marafon (2006) é caracterizada por estabelecimentos onde gestão e trabalho estão intimamente ligados, ou seja, os meios de produção pertencem à família e o trabalho é exercido por esses mesmos proprietários em uma área relativamente pequena ou média. Além da força de trabalho familiar, Hurtienne (1999) também chama a atenção para a questão da indivisibilidade entre as decisões de produção e de consumo.

Os índices relacionados à utilização de agrotóxicos e ao recebimento de orientação técnica para utilizálos encontram-se semelhantes ao trabalho de Vicente (1998). No que se refere ao destino das embalagens vazias de agrotóxicos, Peres e Moreira (2007) já haviam afirmado que somente $10 \%$ ou $20 \%$ retornam à revenda, o que foi confirmado neste agrupamento. A congruência entre as informações sobre cuidados durante o uso de agrotóxicos, ocorrência de intoxicação e morte na família devido ao uso de agrotóxicos leva a crer na existência de um círculo vicioso envolvendo a seguinte seqüência: uso incorreto + falta de cuidado + intoxicação $=$ morte.

As famílias que compõem o grupo $\mathrm{I}$, que correspondem a $83,2 \%$ do total de entrevistas realizadas, conferem uma elevada representatividade dentro do universo de famílias existente na região de estudo, bem como, representatividade dentro da amostragem que envolveu 237 famílias. Verificar estas informações significa dizer que é característica da parte baixa da bacia hidrográfica do riacho Faé, a agricultura familiar; com famílias de baixa renda; que desenvolvem as suas atividades produtivas de maneira rudimentar; que o uso de agrotóxicos representa sérios riscos não só à sustentabilidade do modelo agrícola, mas, principalmente, à vida desses rurícolas.

Registre-se a importância sócio-ambiental e econômica da bacia hidrográfica do riacho Faé, haja vista que a mesma é uma das principais tributárias do açude Orós, que por sua vez se constitui no principal manancial de abastecimento de água para o Médio e o Baixo Jaguaribe, além de ser um importante contribuinte para o abastecimento da Região Metropolitana de Fortaleza.

\section{Formação do Grupo II}

O grupo II reuniu 16,8\% das famílias entrevistadas. As características responsáveis pelo agrupamento foram: faixa etária, grau de instrução, renda familiar, destino final dos dejetos sólidos, abastecimento de água para consumo humano e principal atividade econômica da família. Nesse grupo predomina a faixa etária mais jovem, entre os 18 e 23 anos de idade, com um índice de $64,1 \%$; baixa escolaridade, com $94,8 \%$; renda familiar de até um salário mínimo, com $51,2 \% ; 66,6 \%$ das famílias possuem fossa séptica; o abastecimento de água para consumo humano é feito através de cacimbões e poços $74,3 \%$; a principal atividade econômica da família não é a agricultura. 
É importante frisar que a principal característica deste grupo II é: faixa etária jovem predominante, baixa escolaridade e atividade econômica não agrícola. Provavelmente o que está ocorrendo com este grupo é um processo de proletarização dessas famílias rurais. De acordo com Leite e Ávila (2007) a reforma agrária e a pluriatividade são vistas como políticas que poderiam reduzir significativamente o problema da pobreza rural. Contudo, os autores afirmam que a pluriatividade só poderá ser bem sucedida se os pobres rurais forem qualificados e se houver oportunidades de emprego, com investimento em atividades geradoras de emprego e renda. Segundo Evangelista (2000), apenas os estabelecimentos familiares do Nordeste geram uma renda monetária mensal inferior ao salário mínimo. A agricultura familiar nordestina gera somente $25 \%$ da renda monetária mensal da sua similar no resto do país, o que não é suficiente para assegurar um nível de vida digna para os trabalhadores rurais.

Os dados obtidos na região em estudo se mostram coerentes, pois conforme registrado, $11 \%$ dos entrevistados declararam outros tipos de atividade (pecuarista, pescador, servidor público). Evangelista (2000) constatou que dos 6,4 milhões dos benefícios da Previdência Social (aposentadorias e pensões), mais de 5 milhões de benefícios, se encontravam no meio rural.

Verificou-se que 59\% das famílias entrevistadas, o chefe se enquadrava na faixa etária acima dos 41 anos de idade. Contudo, não é possível perceber o quantitativo na faixa etária a partir dos 65 anos de idade, quando já se faz jus aos benefícios do INSS devido à idade, bem como, não se sabe o percentual de pensionistas devido à viuvez e/ou por motivos de saúde. Certamente um percentual dessas famílias depende desses benefícios.

Na região em estudo já se observa a ocorrência de famílias pluriativas, com um número diversificado de possibilidades, tais como: atividades comerciais desenvolvidas no interior das residências, como por exemplo, pequenos bares e mercearias, geralmente no primeiro cômodo da casa; filhos mais novos trabalhando em empresas da sede do município de Quixelô e/ou em Iguatu; pelo menos um membro da família trabalhando como servidor público municipal, seja como auxiliar administrativo, seja como docente, principalmente, as mulheres absorvidas pela educação infantil e o ensino fundamental; mesmo aposentados, é comum no meio rural as pessoas idosas ainda trabalhando na agricultura.

O mosaico de atividades laborais dos rurícolas inseridos na parte baixa da bacia hidrográfica do riacho Faé se mostra bastante complexo. Isto porque as comunidades que fizeram parte desta pesquisa se localizam muito próximas à sede do município de Quixelô, que por sua vez também está muito próximo do município de Iguatu, de onde já foi um distrito deste último.

Observa-se que no grupo II ocorre uma maior incidência de atividades tanto no comércio como na indústria. Provavelmente os jovens da região em estudo estão sendo absorvidos pelo comércio local de Quixelô e/ou pelas grandes indústrias pertencentes ao Distrito Industrial de Iguatu, a exemplo da Dakota, Tub Form, Made Form, além de diversas metalúrgicas de menor porte e expressão econômica.

Embora ainda não seja representativo, detectar que já é fato o processo de proletarização dos trabalhadores rurais da região estudada lança uma série de preocupações futuras. Conforme os dados obtidos, principalmente relacionados a grau de instrução, idade dos chefes de família, renda per capita familiar, encolhimento da família e qualidade de vida no meio rural, é cabível supor que poderá vir a acontecer na região estudada o que já está acontecendo no meio rural do Estado de Santa Catarina. Conforme relatado por Abramovay (2000), em Santa Catarina os estabelecimentos de agricultura familiar se encontram habitados por casais com mais de 41 anos de idade sem a presença de jovens e/ou com apenas 1 filho, futuramente colocando em risco a continuidade das atividades agrícolas familiares na parte baixa da bacia hidrográfica do riacho Faé.

\section{Conclusões}

1. A análise de agrupamento se mostrou eficiente ferramenta para a distinção dos grupos de famílias homogêneas na área estudada, independentemente de sua localização geográfica;

2. O grupo I, com $83,2 \%$ das famílias pesquisadas, caracteriza-se por famílias de baixa renda, com seu chefe possuindo baixa escolaridade, utilizando agrotóxicos de maneira indiscriminada, com registro de intoxicações e óbitos devido ao uso de agrotóxicos e irrigando por inundação;

3. O grupo II, com $16,8 \%$ das famílias pesquisadas, embora localizadas no meio rural apresentou características tipicamente urbanas e podem ser classificadas como famílias pluriativas;

4. O estudo de caso realizado na região do Faé trouxe à tona uma realidade de sobrevivência bastante cruel a que estão submetidos aqueles trabalhadores rurais. Os resultados da pesquisa de campo demonstram a urgente necessidade de intervenção do poder público no sentido de promover mudanças consideráveis nos diversos indicadores aqui registrados. 


\section{Agradecimentos}

Os autores agradecem ao Conselho Nacional de Desenvolvimento Científico e Tecnológico - CNPq e a Coordenação de Aperfeiçoamento de Pessoal de Nível Superior-CAPES pelo apoio financeiro dado a esta pesquisa.

\section{Referências}

ABRAMOVAY, R. Agricultura familiare novas oportunidades de acesso à terra. Gazeta Mercantil, São Paulo, Caderno A3, 30 nov. 2000.

ALBUQUERQUE, M. A. Estabilidade em análise de agrupamento: estudo de caso em ciência florestal. Viçosa-MG: Revista Árvore, v. 30, n. 02, p. 257-265, 2006.

BRANCO, M. C. Avaliação do conhecimento do rótulo dos inseticidas por agricultores em uma área agrícola do Distrito Federal. Revista Horticultura Brasileira, v. 21, n. 03, p. 570-573, 2003.

CHRISTOFIDIS, D. Água, ética, segurança alimentar e sustentabilidade ambiental. Salvador - BA: Bahia Análise \& Dados, v. 13, n. Especial, p. 371/82, 2003.

DUTRA, I. S.; SAUAIA, A. C. Alianças em rede de empresas no laboratório de gestão empresarial. Fortaleza: Revista Ciências da Administração, v. 13, n. 02, p. 317-327, 2007.

EVAngelista, F. R. A Agricultura familiar no Brasil e no Nordeste. Fortaleza: BNB, 2000. Série Documentos do ETENE.

FERREIRA, M. O. et al. Especialização produtiva e mudança estrutural da agropecuária cearense. Passo Fundo: Revista Teoria e Evidência Econômica, v. 14, n. 26, p. 91-111, 2006.

HURTIENNE, T. A Agricultura familiar e o desenvolvimento sustentável: problemas conceituais e metodológicos no contexto histórico da Amazônia. Fortaleza: Revista Econômica do Nordeste, v. 30, n. Especial, p. 442-466, 1999.

LEITE, S. P.; ÁVILA, R. V. Um futuro para o campo: reforma agrária e desenvolvimento social. Rio de Janeiro: Vieira \& Lent, 2007. 176p. Coleção Ciência no Bolso.
LOPES, F. B. Índice de sustentabilidade do perímetro irrigado Baixo Acaraú, Ceará. Dissertação (Mestrado em Agronomia Irrigação e Drenagem) Universidade Federal do Ceará, Fortaleza, CE. 121f. 2008.

LOPES, F. B. et al. Índice de sustentabilidade do perímetro irrigado Baixo Acaraú, Ceará, empregando análise multivariada. Revista Ciências Agronômica, v. 40, n. 01, p. 17-26, jan-mar, 2009.

MARAFON, G. J. Agricultura familiar, pluriatividade e turismo rural: reflexões a partir do território fluminense. Uberlândia: Revista de Geografia Agrária, v. 01, n. 01, p. 17-60, 2006.

MARTEL, J. H. I. et al. Estatística multivariada na discriminação de raças amazônicas de pupunheiras (Bactris gasipaes Kunth) em Manaus (Brasil). Jaboticabal: Revista Brasileira de Fruticultura, v. 25, n. 01, p. 115-118, 2003.

MOORE, D. S.; McCABE, G. P. Introdução à prática da estatística. Trad. FARIAS, A. A.

Rio de Janeiro: LTC Editora, 2002. 536p.

NASCIMENTO, C. A. Aspectos da agricultura familiar regional: Nordeste e Sul - 1996 a 2001 e 2001 a 2004. Uberlândia: Revista Parcerias Estratégicas, Edição Especial, n. 22, p. 317-345, 2006.

NOGUEIRA, F. R. B.; SIMÕES, S.V.D. Uma abordagem sistêmica para a agropecuária e a dinâmica evolutiva dos sistemas de produção no Nordeste Semiárido. Mossoró: Revista Caatinga, v.22, n. 02, p. 01-06, 2009.

PERES, F.; MOREIRA, J. C. Saúde e ambiente em sua relação com o consumo de agrotóxicos em um pólo agrícola do Estado do Rio de Janeiro, Brasil. Rio de Janeiro: Cadernos de Saúde Pública, v. 23, Suplemento n. 4, p. 5612-5621, 2007.

RABELO, L. S. Indicadores de sustentabilidade: a possibilidade do desenvolvimento sustentável. Fortaleza: Prodema, UFC, 2008. 126p.

SOUZA, D. R. et al. Emprego de análise multivariada para estratificação vertical de florestas ineqüiâneas. Viçosa-MG: Revista Árvore, v. 27, n. 01, p. 59-63, 2003.

SOUZA, G. H. F. et al. Desempenho do Distrito de Irrigação Senador Nilo Coelho. Revista Brasileira de Engenharia Agrícola e Ambiental, v. 05, n. 02, p. 204-209, 2001.

VICENTE, M. C. M. Perfil do aplicador de agrotóxicos na agricultura paulista. São Paulo: Revista de Informações 